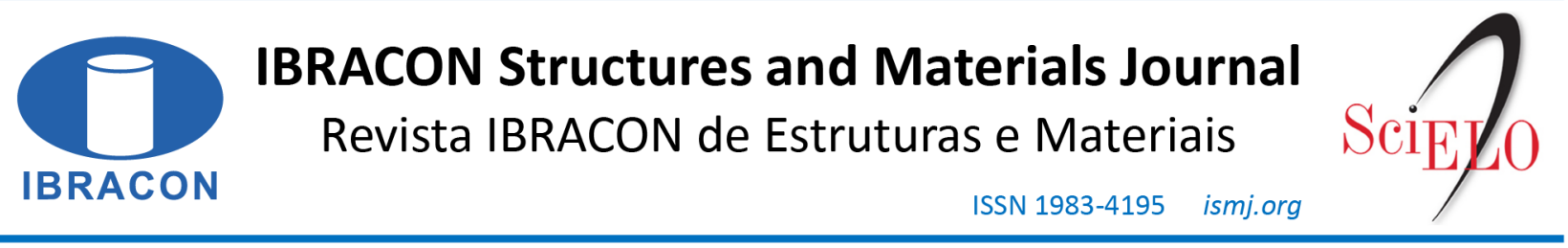

ORIGINAL ARTICLE

\title{
Analysis of nodal stress on reinforced concrete two-pile caps supported on steel piles
}

\section{Análise das tensões nodais em blocos de concreto armado apoiado sobre duas estacas metálicas}

\author{
Rodrigo Gustavo Delalibera ${ }^{\mathrm{a}}$ (iD \\ Marco Aurélio Tomaz ${ }^{\mathrm{a}}$ \\ Vitor Freitas Gonçalves ${ }^{\mathrm{a}}$ (D) \\ José Samuel Giongo ${ }^{\mathrm{b}}$
}

\author{
${ }^{a}$ Universidade Federal de Uberlândia, Faculdade de Engenharia Civil, Uberlândia, MG, Brasil

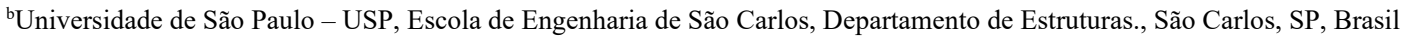

Received 14 June 2018

Accepted 04 May 2020

\begin{abstract}
Reinforced concrete pile caps may be designed trough plastic models (strut and tie model) or models based on bending theory. The formulae available for verifying the stress is based on caps supported on concrete piles, with few studies about the stress distribution on caps supported on steel piles. To analyze the structural behavior of caps supported on steel piles, as well as the stress on the superior and inferior nodal zones, four two-pile caps supported on steel piles were tested. The variables were the embedment length and in one of the specimens a steel plate was welded on top of both piles. It was observed that the embedment length has substantial influence on pile cap structural behavior. It was concluded that, to verify the stress on inferior nodal zone of the cap, aside from pile area, an area of concrete confined between the flaps of the pile must be considered.
\end{abstract}

Keywords: pile caps, steel piles, strut and tie model, nodal stress.

\begin{abstract}
Resumo: Blocos de concreto armado sobre estacas podem ser dimensionados por meio de modelos plásticos (Modelo das bielas e tirantes) ou modelos baseados na teoria da flexão. A formulação disponível para a verificação das tensões é baseada em blocos apoiados sobre estacas de concreto, sendo que existem poucos estudos abordando a distribuição de tensões em blocos sobre estacas metálicas. Com o intuito de analisar o comportamento estrutural de blocos apoiados sobre estacas metálicas e as tensões que surgem nas zonas nodais superior e inferior, foram ensaiados quatro modelos de blocos sobre duas estacas metálicas. As variáveis foram o comprimento de embutimento do perfil dentro do bloco e em um dos modelos foi soldada uma chapa de aço quadrada no topo das estacas. Observou-se que o embutimento interfere de maneira significativa no comportamento estrutural do bloco. Concluiu-se que, para a verificação das tensões na zona nodal inferior do elemento deve ser considerada, além da área da estaca, uma área de concreto confinado entre as abas do perfil.
\end{abstract}

Palavras-chave: blocos sobre estacas, estacas metálicas, modelo de bielas e tirantes, tensões nodais.

How to cite: R. G. Delalibera, M. A. Tomaz, V. F. Gonçalves, and J. S. Giongo, “Analysis of nodal stress on reinforced concrete two-pile caps supported on steel piles," Rev. IBRACON Estrut. Mater., vol. 13, no. 6, e13612, 2020, https://doi.org/10.1590/S1983-41952020000600012

\section{INTRODUCTION}

According to NBR 6118: 2014 [1], pile caps are volumetric structural elements whose function is to transfer the loads from the superstructure to the infrastructure. Despite being essential for the safety and durability of a structure, pile caps are generally buried elements and, therefore, do not allow visual inspection when in service. The dimensioning of these elements can be performed by three-dimensional calculation models (linear or not) or strut and tie models, the 
latter being preferred by engineers due to the possibility of dimensioning in plastic regime. The strut and tie models, for the analysis of stresses in the nodal regions, were elaborated with the premise of reinforced concrete blocks supported on concrete piles. The works of Blévot and Frémy [2], Schlaich and Schäfer [3] and Fusco [4] can be highlighted, as a reference for the study of pile blocks.

According to Xiao and Chen [5] and Velloso and Lopes [6], the use of metal piles provides some advantages in relation to concrete piles, such as the possibility of driving in soils that are difficult to transpose, high resistance to bending and traction, ease of cutting, splicing and transport. Even though they are widely used in bridges, viaducts, ports and containment structures, few studies on the use of metal piles in concrete blocks are found in the technical literature. Therefore, there are still questions about how embedded the metal pile should be in the block, how the connection between block and pile should be made, how the tension in the nodal region should be calculated and what is the maximum allowed tension in this region.

According to the SODH [7] (State of Ohio Department of Highways), piles designs on metal piles have been carried out on the premise that it is necessary to use a steel plate on top of the piles to prevent a concentration of stresses in the connection region between the block and the piles. According to NBR 6122:2010 [8], this connection must be made by means of plates, chartering or rebar welding.

SODH [7] conducted a large number of pile caps tests on a centered metal pile. In total, 47 pile caps were tested, varying the concrete used, the cross section of the pile, the length of the pile embedded within the pile cap, the height of the pile cap, presence or not of a welded steel plate at the top of the pile, the type of the frame of the pile caps and the type of support. Reinforced concrete pile caps with stirrups were used according to the sides of the block, with circular stirrups and simple concrete blocks. The SODH [7] concluded that the use of a sheet at the top of the pile does not increase the bond strength and, in the tests in which failure occurred in the concrete, the main cause was the appearance of tensile stresses transversal to the compressive stresses (diagonal traction, also called connecting rod splitting), due to the partially loaded block effect.

Slutter [9] rehearsed two pile caps on six metal piles. The pile caps were in real scale and rectangular in shape, with frames only in the horizontal plane and in mesh. In one of the pile caps, the author welded steel plates welded on top of two of the six piles, also verifying that the plates do not influence the bearing capacity of the block or the length of penetration of the piles within the element. In addition, Slutter [9] observed failure in the reinforcement anchoring, concluding that the distance between the axis of the piles and the edge of the block must be sufficient to allow the fulfillment of the anchoring requirements.

Xiao and Chen [5] studied one pile caps on piles in metallic profile with horizontal forces or tensile forces acting on the tip of the piles, in order to assess the resistance of the connection between the piles and the block under a situation of earthquake. The tested block had mesh reinforcement and comprised 16 piles, and for the piles subject to tension, two types of connection were tested. Xiao and Chen [5] concluded that the ultimate horizontal force is directly related to the axes of inertia of the profile, with greater resistance when the force is applied in the direction perpendicular to the axis of greater inertia of the profile. Regarding the traction force, there was no significant difference between the types of anchorage tested. In order to analyze the behavior of pile caps supported on metal piles, as well as to verify the stresses that arise in the nodal regions of the element, four pile caps supported on two metal piles were tested. The variables of the models studied were the length of the pile embedded in the pile caps and, in one of the models, steel plates were welded on top of the piles. The use of a steel plate on the top of the piles was made to analyze the hypothesis that this plate increases the area of the top of the pile, decreasing the tension in this region and, consequently, improving the structural behavior of the pile cap.

\section{CRITERIA USED FOR DESIGN}

Four pile caps were tested on two metal piles, with inlay lengths equal to $10 \mathrm{~cm}, 20 \mathrm{~cm}$ and $30 \mathrm{~cm}$. In one of the pile caps with $10 \mathrm{~cm}$ inlay, square steel plates with $25 \mathrm{~cm}$ edges and thickness equal to the thickness of the section web $(39 \mathrm{~mm})$ were welded on top of the piles. The name given to each of the four models is in accordance with the following:

- BEmb10sch: Pile cap with $10 \mathrm{~cm}$ inlay, without top plate;

- BEmb10cch: Pile cap with $10 \mathrm{~cm}$ inlay, with top plate;

- BEmb20sch: Pile cap with $20 \mathrm{~cm}$ inlay, without top plate;

- BEmb30sch: Pile cap with $30 \mathrm{~cm}$ inlay, without top plate. 
The models were dimensioned in accordance with the criteria of Blévot and Frémy [2] and the recommendations of NBR 6118:2014 [1], with the proviso that no additional reinforcement was used in addition to the main traction reinforcement (in other words, tie), as recommended by the Brazilian standard. This was done with the objective of minimizing the interference of steel bars in nodal stresses.

NBR 6118:2014 [1] classifies the pile caps as rigid or flexible, considering if the rigid pile caps work with flexion in both directions, with concentrated tension in the line on the piles and shear in both directions, and transmits the column forces to the piles by means of compression connecting rods (or struts). As for the flexible pile caps, NBR 6118:2014 [1] recommends a more complete analysis because their rupture can be defined by the puncture effect. The use of flexible pile caps is not recommended, as there is a need to use transverse reinforcement to resist the tensile stresses caused by shear stresses.

The classification as to the rigidity of the pile caps, by NBR 6118:2014 [1] is geometric, which may lead to contradictory results, as for example, in a situation of an elongated pillar. According to the Brazilian standard, a block is considered rigid, if the total height of the block is greater than or equal to the difference in block length, minus the column dimension in the same direction, divided by three, $h \geq\left(a-a_{p} / 3\right)$, with "a" dimension of the pile cap in a given direction, " $a \mathrm{p}$ " the dimension of the column in the same direction and " $\mathrm{h}$ " the total height of the pile cap. Applying to the previous expression, for an elongated pillar, it is possible to have a block classified as rigid, for a height considered small for it. Therefore, it is suggested that the classification of the pile cap stiffness be made by the angle of inclination of the strut in relation to the horizontal plane of the pile cap.

The Brazilian standard, NBR 6118:2014 [1], suggests strut and tie models for the design of pile caps. Applying this model, contained in that standard, the inclination of the strut in relation to the horizontal plane must be between $29.7^{\circ}$ and $63.4^{\circ}$. According to Blévot and Frémy [2], the pile cap is considered rigid if the angle formed between the strut and the horizontal plane of pile cap is between $45^{\circ}$ and $55^{\circ}$.

Applying the Blévot and Frémy model [2], based on Figure 1, it was determined that the distance between the longitudinal axis of the pile up to the face of the column plus $1 / 4$ of its dimension is equal to $25 \mathrm{~cm}$, and the useful height of the pile cap (measured from the top of the pile to the upper face of the block) is equal to $25 \mathrm{~cm}$, thus forming an angle of $45^{\circ}$.

Thus, it is concluded that the pile caps tested are rigid, because the strut angle in relation to the horizontal plane of the pile cap, respects the recommendations of NBR 6118:2014 [1] and Blévot and Frémy [2].

The Brazilian standard does not present specific criteria for the design of pile cap or guidelines for the case of pile caps on metal piles, it only limits the compression stresses in the nodal regions. For pile caps on two piles, NBR 6118: 2014 [1] recommends that stresses in the upper (CCC Node) and lower (CCT Node) nodal zones should be limited by Equations 1 and 2, where: $\sigma_{\mathrm{zns}}$ is the tension in the upper nodal zone; $\sigma_{\mathrm{zni}}$ is the tension in the lower nodal zone; fc is the uniaxial compressive strength of concrete. CCC nodes are understood as nodes where there are only compression forces, CCT nodes are nodes where there are compression forces, a tensile force and $\sigma_{\mathrm{zn}}$ is the normal tension in the nodal region, defined by the ratio between the compression force and the area of the strut, see Figure 1.

$\sigma_{\mathrm{zns}} \leq 1.0 \cdot \mathrm{f}_{\mathrm{c}}$

$\sigma_{\mathrm{zni}} \leq 0.847 \cdot \mathrm{f}_{\mathrm{c}}$

where $f_{c}$ is the compressive strength of concrete.

In this paper, the factors that reduced concrete strength related to creep and the $\alpha_{\mathrm{v} 2}$ coefficient were not considered. This procedure was adopted, as it was intended to measure the experimental results against the limits established by the referred norm. For the lower nodal zone, the existence of cracks crossing the connecting rods was considered (this effect is considered in NBR 6118: 2014 [1] by multiplying the value of $f_{c}$ by 0.72 ). Thus, in order not to consider the effect of long-term loads in the lower zone, the value of $\mathrm{f}_{\mathrm{c}}$ was multiplied by 0.847 . It is worth mentioning that the values presented by NBR 6118:2014, for nodal stresses are: $\sigma_{\mathrm{zns}} \leq 0.85 \cdot \alpha_{\mathrm{v} 2} \cdot \mathrm{f}_{\mathrm{cd}}$, for the upper zone and $\sigma_{\mathrm{zni}} \leq 0.72$. $\alpha_{\mathrm{v} 2} \cdot \mathrm{f}_{\mathrm{cd}}$, for the inferior nodal zone. Disregarding the value of 0.85 , related to long-term loads in the two equations, the tensions in the upper and inferred node regions are obtained, respectively. 


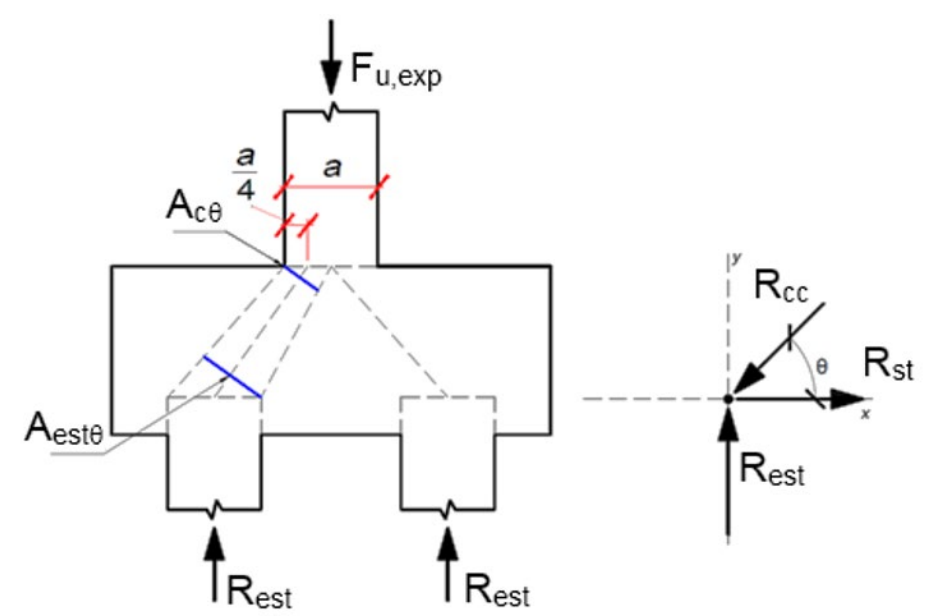

Figure 1. Strut and tie model proposed by Blévot and Frémy [2].

According to Blévot and Frémy [2], in the case of a pile cap supported on two piles, the axis of the strut is formed from the axis of the pile up to $1 / 4$ of the outer face of the column and, for the calculation of nodal stresses, the areas are considered of the pile and the column projected in the direction transverse to the strut. Figure 1 illustrates the model proposed by Blévot and Frémy [2] for the case of a pile cap supported on two piles, in which: $F_{u, e x p}$ is the ultimate force applied to the column; "a" is the dimension of the column in the longitudinal direction of the pile cap, $\mathrm{A}_{\mathrm{c}}$ is half the pillar area; $A_{\text {est }}$ is the pile area; $\theta$ is the angle between the axis of the strut in relation to the horizontal plane; $R_{\text {est }}$ is the reaction in the pile; $R_{c c}$ is the compression force on the strut; $R_{s t}$ is the force in the tie. The stresses in the upper and lower nodal zones are calculated using Equations 3 and 4, respectively.

$\sigma_{\mathrm{zns}}=\frac{F_{\mathrm{u}, \exp }}{\mathrm{A}_{\mathrm{c}} \cdot \operatorname{sen}^{2}(\theta)}$

$\sigma_{\mathrm{zni}}=\frac{\mathrm{F}_{\mathrm{u}, \mathrm{exp}}}{2 \cdot \mathrm{A}_{\mathrm{est}} \cdot \operatorname{sen}^{2}(\theta)}$

The force in the $\mathrm{R}_{\mathrm{st}}$, necessary for the dimensioning of the main reinforcement, is achieved through the static balance of forces of the lower nodal zone. Blévot and Frémy [2] recommend that the angle between the compression rod and the horizontal plane be $45^{\circ}$ to $55^{\circ}$ and that the stresses in the nodal regions should have the limits shown in Equations 5 and 6. In Equations 5 and 6, the concrete material lessening coefficients, the coefficient related to long-term loads and the confinement effect in CCC type nodes, caused by the concrete resistance in the multiaxial state of stresses, were not considered.

$\sigma_{\mathrm{zns}} \leq 0,60 \cdot \mathrm{f}_{\mathrm{c}}$

$\sigma_{\text {zni }} \leq 0,60 \cdot f_{c}$

\section{MECHANICAL AND GEOMETRIC PROPERTIES OF MODELS}

The parameters fixed in all models were: the angle between the strut and the horizontal direction $(\theta)$ of $45^{\circ}$; height of $35 \mathrm{~cm}$; width of $25 \mathrm{~cm}$; $139.5 \mathrm{~cm}$ length; cross section of the $25 \times 25 \mathrm{~cm}^{2}$ column. For the piles, the W200 $\times 15$ metal profile was used, positioned with the axis of greater inertia in the same direction as the pile cap width and cut so as to have the same length outside the pile cap in all models, varying only its embedded length. Table 1 shows the geometric properties of the models tested. 
For the metallic profile, a yield stress of $345 \mathrm{MPa}$ was considered, following the recommendations of NBR 8800:2008 [10]. As mentioned previously, reinforcement was used only on the tie, calculated so as not to reach the yield stress. For this, the balance of the lower nodal region was made considering the ultimate force supported by the metallic profile and under the premise that the force applied to the column is centered and the reactions in both piles are equal. The reinforcement was calculated considering the yield stress characteristic of CA-50 steel equal to $500 \mathrm{MPa}$, according to the guidance of NBR 6118:2014 [1]. Four bars of $20 \mathrm{~mm}$ in diameter were used, and the length of reinforcement anchoring, measured from the internal face of the piles to the external face of the pile cap, was verified according to the recommendations of NBR 6118:2014 [1]. In order to bring about the ruin to occur in the pile cap, the column was dimensioned considering the reduction coefficients of the strengths of the materials and increase of the soliciting efforts and, in addition, concrete with a compressive strength of $50 \mathrm{MPa}$ was adopted. For the pile caps, $20 \mathrm{MPa}$ was considered. Opted for concrete with a $20 \mathrm{MPa}$ resistance to compression due to the support capacity of the reaction frame available at the Structural Laboratory of the Federal University of Uberlândia, where all tests were carried out. A height that was considered sufficient for the dissipation of tensions was adopted for the pillar, so that the second order effects could be neglected according to the Saint-Venant principle. The pillar was constructed with 8 bars of $10 \mathrm{~mm}$ in diameter and stirrups of $6.3 \mathrm{~mm}$ in diameter, spaced ever $2.5 \mathrm{~cm}$. Figures 2 and 3 illustrate the geometric properties and the reinforcement arrangement of the models.

Table 1 - Geometric parameters of pile caps.

\begin{tabular}{ccccccc}
\hline Model & Height (cm) & $\begin{array}{c}\text { Pile axis distance } \\
(\mathbf{c m})\end{array}$ & $\begin{array}{c}\text { Pile cap length } \\
(\mathbf{c m})\end{array}$ & Width (cm) & $\begin{array}{c}\text { Column section } \\
(\mathbf{c m} \times \mathbf{~ c m})\end{array}$ & $\begin{array}{c}\text { Total pile length } \\
(\mathbf{c m})\end{array}$ \\
\hline BEmb10sch & 35 & 62.5 & 139.5 & 25 & $25 \times 25$ & 35 \\
\hline BEmb10cch & 35 & 62.5 & 139.5 & 25 & $25 \times 25$ & 35 \\
\hline BEmb20sch & 35 & 62.5 & 139.5 & 25 & $25 \times 25$ & 45 \\
\hline BEmb30sch & 35 & 62.5 & 139.5 & 25 & $25 \times 25$ & 55 \\
\hline
\end{tabular}

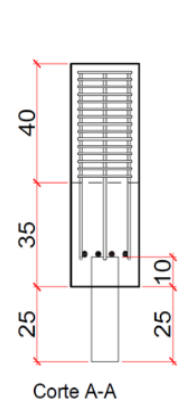

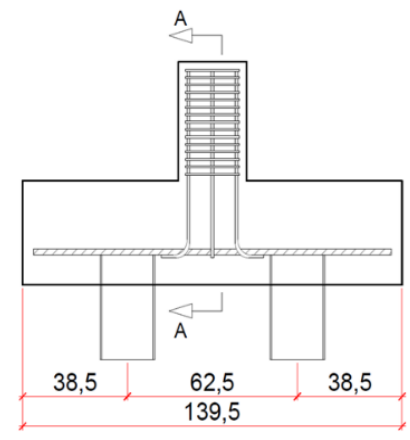

BEmb10sch

Figure 2. Models BEmb10sch and BEmb10 cch (dimensions in $\mathrm{cm}$ ).
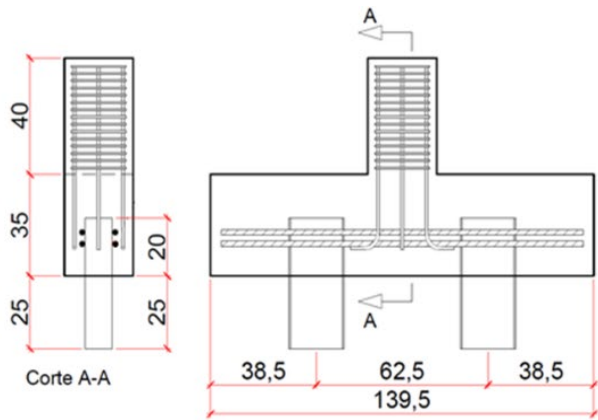

BEmb20sch

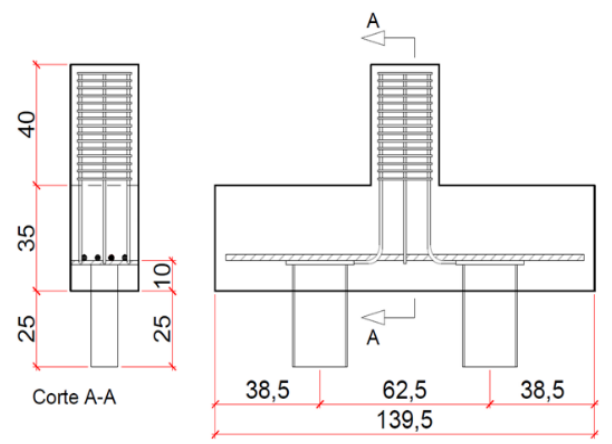

BEmb10cch
(dimensions in $\mathrm{cm})$

Figure 3. Models BEmb20sch and BEmb30sch (dimensions in $\mathrm{cm}$ ) 


\section{CHARACTERIZATION OF MATERIALS AND EXPERIMENTAL TESTS}

To define the properties of the metal profiles, each of the 8 pieces was weighed and its dimensions were obtained using a caliper. Figure 4 shows the dimensions measured in each profile and Table 2 shows the results of the measurements. For the calculation of the cross-sectional area of the profile, the circular sections, present between the flaps and the core of the part, were approximated to rectangular triangles of legs equal to $0.7 \mathrm{~cm}$. Table 3 shows the geometric properties of the metal profiles, in which: $\mathrm{I}_{\mathrm{x}, \mathrm{cg}}$ is the moment of inertia in relation to the horizontal axis that passes through the $\mathrm{CG}$ of the part; $\mathrm{I}_{\mathrm{y}, \mathrm{cg}}$ is the moment of inertia in relation to the vertical axis that passes through the CG of the steel profile.

For the main frame of the pile caps and columns, CA-50 steel was used, characterized by tensile tests according to the recommendations of NBR 6892-1:2013 [11]. Table 4 shows the mechanical properties of the steel used, where: $\mathrm{f}_{\mathrm{y}}$ is the yield strength; $\varepsilon_{\mathrm{y}}$ is strain deformation; $\mathrm{f}_{\mathrm{u}}$ is stress ultimate; $\mathrm{E}$ it is the longitudinal strain module.

For $20 \mathrm{MPa}$ concrete, cement with the addition of CPIV-32-RS pozzolan was used, with a mixture of 1:2.55:3.54:0.68 (cement, sand, crushed stone and a/c) and, for $50 \mathrm{MPa}$ concrete, high-strength CPV initial cement was used, with mix proportion of 1:2.66:3.66:0.49 and 1.5\% of superplasticizer additive. The characterization of the concrete used was carried out by means of compression tests, diametrical compression and test of determination of the initial tangent deformation module, following the recommendations of the standards NBR 5739:1994 [12], NBR 7222: 2011 [13] and NBR 8522:2008 [14]. For each model, 17 cylindrical specimens of $10 \mathrm{~cm}$ in diameter and $20 \mathrm{~cm}$ in height were molded, 8 specimens with concrete used in the pillars, and 9 specimens with concrete used in the pile caps.

Due to the volume of total concrete required, it was not possible to mold all models on the same day. The specimens remained in saturated cure until the test date and were tested on the same day as the pile caps. Table 5 presents the results of the compression tests, in which: $f c$ is the compressive strength of the concrete; $f_{c, m}$ is the average of the compressive strengths presented by the specimens. It is noteworthy that there was a discrepancy in the results of the compressive strength of one of the tested pile caps, causing a decrease in the strength of the concrete. However, this did not harm the analysis, since the premise that the compressive strength of the columns is higher than that of the pile caps was verified. Table 6 shows the result of the diametrical compression tests, where: $F$ is the maximum force; $d$ is the diameter of the specimen; $\mathrm{L}$ is the height of the specimen; $\mathrm{f}_{\mathrm{ct}, \mathrm{sp}}$ is the tensile strength by diametrical compression.

Table 2 - Cross section measurements of W200×15 steel profiles

\begin{tabular}{|c|c|c|c|c|c|c|c|c|c|c|c|}
\hline Profile & $\begin{array}{c}\text { Weight } \\
\text { (kg) }\end{array}$ & $\begin{array}{c}\text { Length } \\
(\mathrm{cm})\end{array}$ & $\begin{array}{c}\text { Linear } \\
\text { mass } \\
(\mathrm{kg} / \mathrm{m})\end{array}$ & $\mathbf{t}_{\mathrm{f} 1}(\mathbf{m m})$ & $t_{\mathrm{f} 2}(\mathrm{~mm})$ & $\mathbf{t}_{\mathbf{f 3}}(\mathbf{m m})$ & $\mathbf{t}_{\mathbf{f} 4}(\mathbf{m m})$ & $\mathbf{t}_{\mathrm{w}}(\mathbf{m m})$ & $b_{f 1}(\mathbf{m m})$ & $b_{f 2}(\mathbf{m m})$ & $h_{P}(\mathbf{m m})$ \\
\hline 1 & 5.15 & 35.25 & 14.61 & 5.45 & 5.58 & 5.49 & 5.30 & 3.92 & 86.30 & 80.91 & 202.89 \\
\hline 2 & 5.20 & 35.30 & 14.73 & 5.31 & 5.51 & 5.54 & 5.41 & 3.88 & 99.17 & 99.19 & 203.13 \\
\hline 3 & 5.15 & 34.66 & 14.86 & 5.47 & 5.53 & 5.54 & 5.25 & 3.88 & 99.18 & 99.24 & 203.07 \\
\hline 4 & 5.20 & 35.13 & 14.80 & 5.38 & 5.20 & 5.39 & 5.23 & 3.90 & 99.96 & 99.14 & 202.95 \\
\hline 5 & 6.70 & 45.20 & 14.82 & 5.49 & 5.25 & 5.48 & 5.58 & 3.95 & 99.24 & 99.22 & 203.03 \\
\hline 6 & 6.65 & 40.06 & 16.60 & 5.20 & 5.38 & 5.21 & 5.25 & 3.90 & 99.18 & 98.87 & 202.85 \\
\hline 7 & 8.15 & 55.26 & 14.75 & 5.40 & 5.26 & 5.31 & 5.51 & 3.84 & 99.89 & 99.15 & 202.92 \\
\hline 8 & 8.15 & 55.03 & 14.81 & 5.46 & 5.21 & 5.39 & 5.48 & 3.93 & 99.08 & 99.08 & 203.06 \\
\hline \multicolumn{3}{|c|}{ Medium values: } & 15.00 & 5.39 & 5.37 & 5.42 & 5.38 & 3.90 & 97.50 & 98.85 & 202.99 \\
\hline
\end{tabular}

Table 3 - Geometric properties of W200×15 steel section

\begin{tabular}{|c|c|c|c|}
\hline Profile & Area $\left(\mathrm{cm}^{2}\right)$ & $I_{x, c g}\left(\mathrm{~cm}_{4}\right)$ & $I_{y, c g}\left(\mathrm{~cm}^{4}\right)$ \\
\hline 1 & 17.62 & 1205.40 & 53.66 \\
\hline 2 & 19.24 & 1370.99 & 88.78 \\
\hline 3 & 19.25 & 1371.17 & 88.94 \\
\hline 4 & 19.04 & 1348.64 & 87.44 \\
\hline 5 & 19.38 & 1375.13 & 89.07 \\
\hline 6 & 18.90 & 1334.18 & 85.38 \\
\hline 7 & 19.04 & 1355.99 & 88.48 \\
\hline 8 & 19.20 & 1361.73 & 87.63 \\
\hline Medium values: & 18.96 & 1340.41 & 83.67 \\
\hline
\end{tabular}


Table 4 - Mechanical properties of CA-50 steel

\begin{tabular}{ccccc}
\hline Specimen & $\mathbf{f}_{\mathbf{y}} \mathbf{( M P a )}$ & $\mathbf{E}_{\mathbf{y}} \mathbf{( \% )}$ & $\mathbf{f}_{\mathbf{u}}(\mathbf{M P a})$ & $\mathbf{E}(\mathbf{G P a})$ \\
\hline 01 & 562.7 & 2.74 & 686.3 & 205.35 \\
\hline 02 & 575.9 & 2.74 & 695.9 & 210.16 \\
\hline 03 & 570.3 & 2.62 & 692.4 & 217.68 \\
\hline Medium values: & 596.6 & 2.70 & 691.5 & 211.07 \\
\hline
\end{tabular}

Table 7 presents the results of the tests for determining the initial longitudinal tangential deformation module of the concrete, where Eci,exp is the value of the tangential deformation module. The specimens 03 of the pile caps BEmb10cch and BEmb30sch, and the specimen 01 of the column presented different results and, therefore, were disregarded.

The models were instrumented with a displacement transducer, positioned in the middle of the pile cap span, and electrical resistance strain gages, installed on the flaps of the metal profiles and in different positions of the reinforcement. The reinforcement extensometers were placed only on one of the bars and, due to the symmetry of loading and dimensions of the models, it was decided to instrument only one side of the pile cap. Figure 5 shows the positioning of the extensometers in the models.

Table 5 - Concrete compressive strength

\begin{tabular}{|c|c|c|c|c|c|}
\hline Element & Specimen & Age (days) & Slump test (mm) & $\mathbf{f}_{\mathbf{c}}(\mathrm{MPa})$ & $\mathbf{f}_{\mathrm{c}, \mathrm{m}}$ (MPa) \\
\hline \multirow{3}{*}{ BEmb10sch } & 01 & \multirow{3}{*}{96} & \multirow{3}{*}{99} & 17.41 & \multirow{3}{*}{17.95} \\
\hline & 02 & & & 15.47 & \\
\hline & 03 & & & 20.97 & \\
\hline \multirow{3}{*}{ BEmb10cch } & 01 & \multirow{3}{*}{62} & \multirow{3}{*}{94} & 13.06 & \multirow{3}{*}{12.51} \\
\hline & 02 & & & 10.96 & \\
\hline & 03 & & & 13.50 & \\
\hline \multirow{3}{*}{ BEmb20sch } & 01 & \multirow{3}{*}{80} & \multirow{3}{*}{95} & 19.18 & \multirow{3}{*}{17.42} \\
\hline & 02 & & & 16.55 & \\
\hline & 03 & & & 16.52 & \\
\hline \multirow{3}{*}{ BEmb30sch } & 01 & \multirow{3}{*}{74} & \multirow{3}{*}{91} & 17.96 & \multirow{3}{*}{18.07} \\
\hline & 02 & & & 18.45 & \\
\hline & 03 & & & 17.79 & \\
\hline \multirow{3}{*}{ Column } & 01 & \multirow{3}{*}{37} & \multirow{3}{*}{37} & 36.85 & \multirow{3}{*}{43.85} \\
\hline & 02 & & & 43.96 & \\
\hline & 03 & & & 50.74 & \\
\hline
\end{tabular}

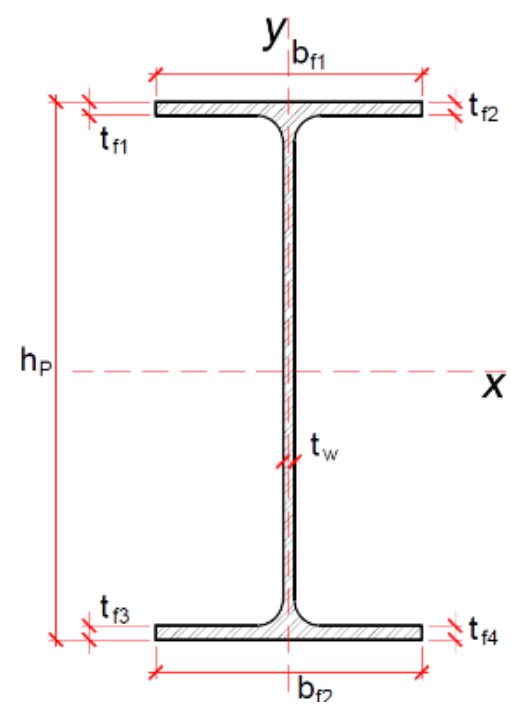

Figure 4. Cross section dimensions of steel profiles 
Table 6 - Concrete tensile strength by diametrical compression

\begin{tabular}{|c|c|c|c|c|c|c|}
\hline Element & Specimen & $\mathbf{F}(\mathbf{N})$ & d (mm) & $\mathbf{L}(\mathbf{m m})$ & $\mathbf{f}_{\mathrm{ct}, \mathrm{sp}}(\mathrm{MPa})$ & Medium values \\
\hline \multirow{3}{*}{$\begin{array}{c}\text { Pile cap } \\
\text { BEmb10sch }\end{array}$} & 01 & 76920.71 & 100.49 & 200.11 & 2.44 & \multirow{3}{*}{2.17} \\
\hline & 02 & 69114.43 & 100.02 & 199.16 & 2.21 & \\
\hline & 03 & 58310.54 & 99.91 & 198.98 & 1.87 & \\
\hline \multirow{3}{*}{$\begin{array}{c}\text { Pile cap } \\
\text { BEmb10cch }\end{array}$} & 01 & 57864.14 & 100.45 & 198.65 & 1.85 & \multirow{3}{*}{1.86} \\
\hline & 02 & 59154.89 & 100.43 & 198.27 & 1.89 & \\
\hline & 03 & 57756.17 & 100.58 & 198.81 & 1.84 & \\
\hline \multirow{3}{*}{$\begin{array}{c}\text { Pile cap } \\
\text { BEmb20sch }\end{array}$} & 01 & 74405.11 & 99.72 & 199.58 & 2.38 & \multirow{3}{*}{2.40} \\
\hline & 02 & 75952.50 & 99.75 & 199.15 & 2.43 & \\
\hline & 03 & 74471.11 & 100.34 & 197.40 & 2.39 & \\
\hline \multirow{3}{*}{$\begin{array}{c}\text { Pile cap } \\
\text { BEmb30sch }\end{array}$} & 01 & 90474.68 & 100.07 & 199.74 & 2.88 & \multirow{3}{*}{2.77} \\
\hline & 02 & 93251.93 & 100.53 & 200.48 & 2.95 & \\
\hline & 03 & 79266.37 & 100.49 & 201.14 & 2.50 & \\
\hline \multirow{2}{*}{ Column } & 01 & 131625.94 & 100.07 & 200.25 & 4.18 & \multirow{2}{*}{4.43} \\
\hline & 02 & 151606.49 & 101.82 & 202.53 & 4.68 & \\
\hline
\end{tabular}

Table 7 - Longitudinal initial tangential deformation module of concrete

\begin{tabular}{|c|c|c|c|}
\hline Element & Specimen & Eci,exp (MPa) & Medium values \\
\hline \multirow{3}{*}{ Pile cap BEmb10sch } & 01 & 28.08 & \multirow{3}{*}{29.26} \\
\hline & 02 & 31.33 & \\
\hline & 03 & 28.36 & \\
\hline \multirow{3}{*}{ Pile cap BEmb10cch } & 01 & 22.39 & \multirow{3}{*}{23.06} \\
\hline & 02 & 23.72 & \\
\hline & 03 & - & \\
\hline \multirow{3}{*}{ Pile cap BEmb20sch } & 01 & 29.49 & \multirow{3}{*}{28.96} \\
\hline & 02 & 29.51 & \\
\hline & 03 & 27.87 & \\
\hline \multirow{3}{*}{ Pile cap BEmb30sch } & 01 & 33.82 & \multirow{3}{*}{31.98} \\
\hline & 02 & 30.15 & \\
\hline & 03 & - & \\
\hline \multirow{3}{*}{ Column } & 01 & - & \multirow{3}{*}{47.81} \\
\hline & 02 & 58.53 & \\
\hline & 03 & 37.09 & \\
\hline
\end{tabular}

The intensity of the force applied to the column was measured by a load cell with a capacity of $2000 \mathrm{kN}$ and, as a reaction structure, the metal frame and the reaction slab from the Structural Laboratory of the Federal University of Uberlândia were used. The column was placed on a support consisting of an elastomer layer and two layers of metal sheets. The pile caps were fixed to the reaction frame to guarantee their lateral stability during the tests. Figure 6 shows the test configuration of the models. More information about the experimental program can be found at Tomaz [15].

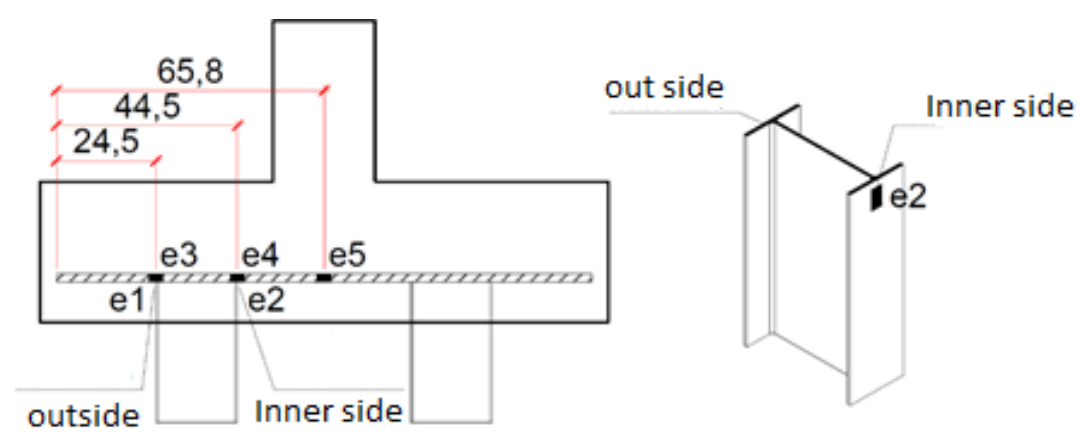

Figure 5. Position of extensometers on models. 


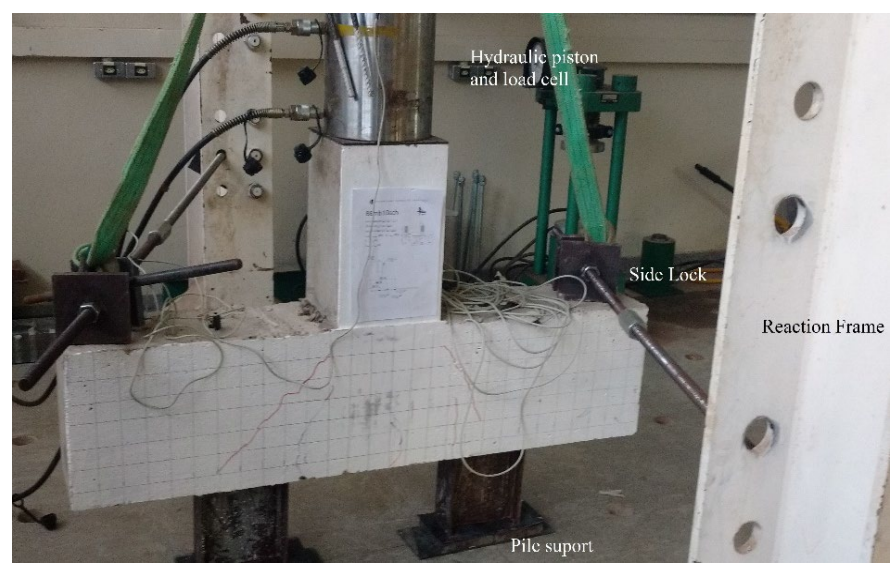

Figure 6. Test-system configuration.

\section{RESULTS AND DISCUSSIONS}

In all models the collapse occurred in the pile cap, that is, both the pillar and the metal post did not show signs of failure and, with the exception of the BEmb30sch model, all the pile caps presented ruin characterized by diagonal traction (strut cracking). The pile caps were tested at the same ages as the respective specimens, indicated in Table 5. Table 8 presents the experimental results, in which: $F_{r}$ is the force related to the first crack; $F_{u, e x p}$ is the ultimate force; $\delta$ is the vertical displacement measured in the middle of the pile cap's span. The ultimate forces were below expectations due to the low compressive strength of the concrete.

In both models with $10 \mathrm{~cm}$ inlay, BEmb10sch and BEmb10cch, the first crack occurred in the lower-central region of the pile and, subsequently, cracks appeared next cap to the internal face of the piles that propagated to the lateral face of the column, in the upper part the pile cap. Both models also had a high $\mathrm{F}_{\mathrm{r}} / \mathrm{F}_{\mathrm{u}, \mathrm{exp}}$, that is, the rupture of the pile cap occurred after the first crack appeared. According to Delalibera and Giongo [16], this relationship can be reduced using horizontal stirrups or steel bars positioned diagonally, crossing struts.

The pile cap with a top plate reached $9 \%$ greater strength than the pile cap with the same inlay and without top plate, even with concrete with $30 \%$ lower strength. Therefore, the use of welded plate at the top of the profile improved the bearing capacity of the pile cap, in contrast to what was observed by Slutter [9], who states that the use of the top plate does not interfere with the structural behavior of the pile cap. Figures 7 and 8 demonstrate the rupture plans observed in the models BEmb10sch and BEmb10cch and, in highlight, the cracks observed next to the pile.

The BEmb20sch model presented two rupture planes, characterized by shear in the compression rod and vertical shear close to the profile flap. Figure 9 shows the rupture planes observed in the BEmb20sch model.

The BEmb30sch model, unlike the others, presented ruin characterized by shearing at the interface of the metallic profile with the upper face of the pile cap (punching), causing the concrete layer to unblock in this region. With this, it became evident that the bonding tension between the profile and the surrounding concrete was not effective and, due to the small thickness of the concrete layer located above the profile, it was not possible to form the compression rods. Consequently, the stresses arising from the reactions in the piles $\left(\mathrm{R}_{\mathrm{est}}\right)$ were transmitted directly to the upper face of the pile cap. Figure 10 shows the cracks observed in the BEmb30sch model and Figure 11 shows a diagram of the rupture lines, similar to the rupture caused by the puncture effect.

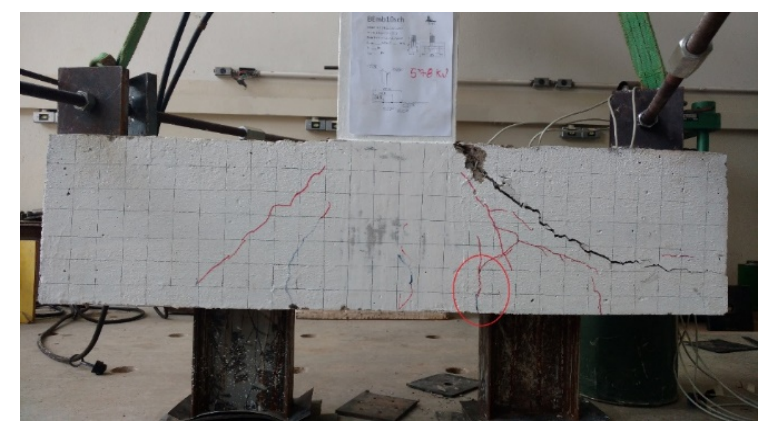

Figure 7. Failure plane of the BEmb10sch model. 


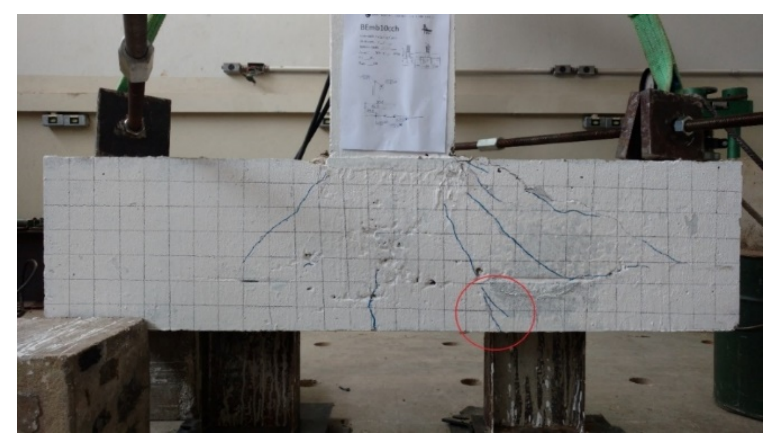

Figure 8. Failure plane of the BEmb10cch model.

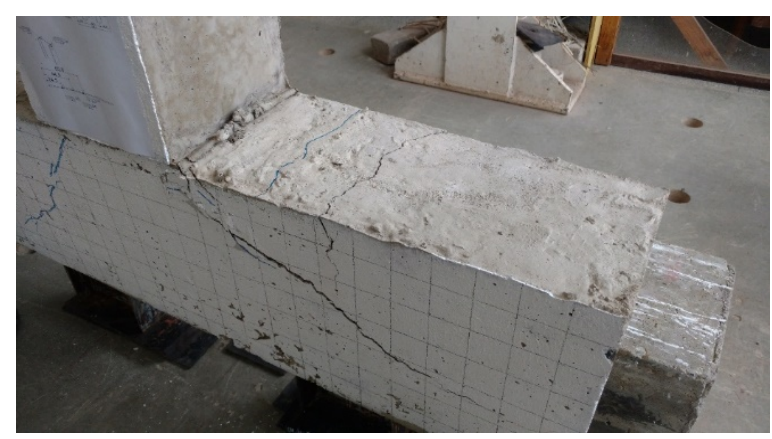

Figure 9. BEmb20sch failure plans.

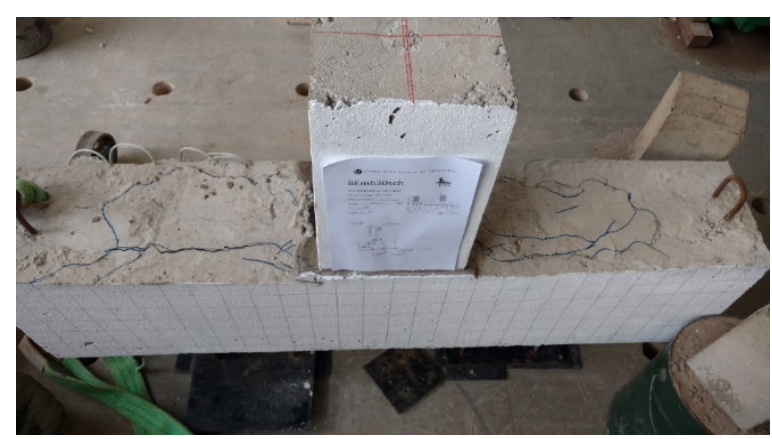

Figure 10. Cracks observed at the top of the model BEmb30sch.

Figure 12 shows the force curves versus vertical displacements of the models. The pile caps with $10 \mathrm{~cm}$ of embedding showed close displacements, indicating that the use of the top plate does not interfere with the rigidity of the pile caps.

The tested pile caps are classified as flexible, according to NBR 6118:2014 [1], which uses pile caps analogous to that of foundation (section 22.6.1). However, for pile caps, where the supports are discrete (piles), the best concept for the rigidity of the element is correlated with the angle of inclination of the strut in relation to the horizontal plane. This consideration was suggested a priori by Blévot and Fremy [2] and is described in section 22.3.1 of NBR 6118:2014 [1]. Thus, all tested models, with the exception of BEmb30sch, have rigid pile cap behavior. The BEmb30sch model presented a flexible pile cap behavior because it was not possible to observe the formation of struts experimentally, even though it is considered geometrically rigid. Therefore, the effect of embedding the piles in the inner part of the pile cap, changed its classification regarding rigidity.

In models with $10 \mathrm{~cm}$ inlay (embedded), the longitudinal reinforcement was positioned above the profile, which caused a pin effect. In this way, if the profile tends to penetrate the pile cap, the bars above it would prevent it. This contributed for the model without a plate to show stiffness close to the model with a plate. In the models with 20 and $30 \mathrm{~cm}$ inlay, the reinforcement was welded on the sides of the profiles and, therefore, this effect did not occur. 


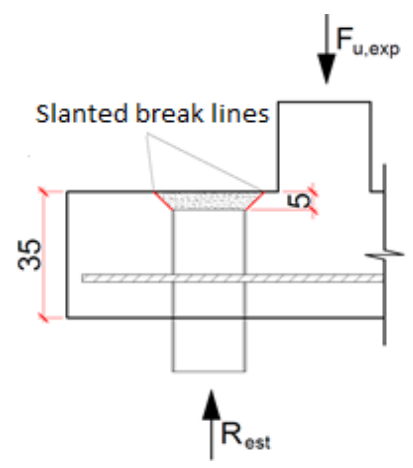

Figure 11. BEmb30sch break lines.

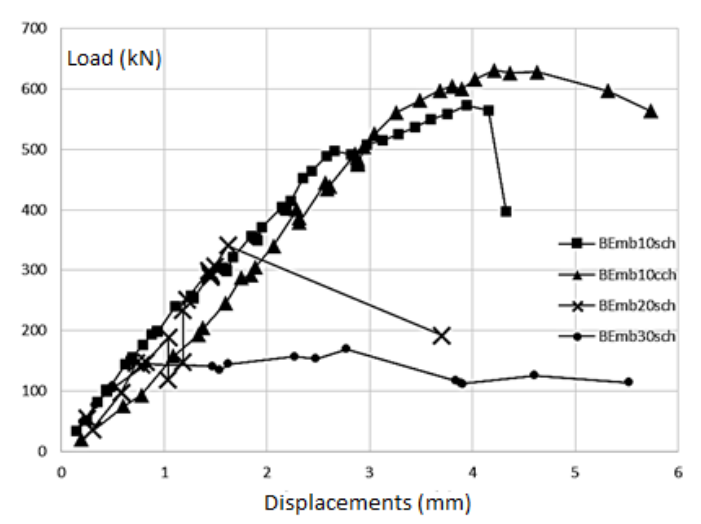

Figure 12. Load vs. displacements.

The deformations related to $\mathrm{F}_{\mathrm{u} \text {,exp }}$ in the bars and profiles, can be seen in Table 8 , in which the extensometers are named according to Figure 5. Figures $13,14,15$ and 16 show the deformations referring to $F_{r}$ and $F_{u, e x p}$ in the reinforcements and profiles. Some strain gauges, whose readings are not shown, showed defects during the tests.

Table 8 - Deformations in the reinforcement and profiles referring to $F_{u \text {,exp }}$

\begin{tabular}{|c|c|c|c|c|c|}
\hline \multirow{2}{*}{ Pile cap } & \multicolumn{2}{|c|}{ Steel profile } & \multicolumn{3}{|c|}{ Steel bar } \\
\hline & e1 (\%o) & e2 (\%o) & e3 (\%o) & e4 (\%o) & e5 (\%o) \\
\hline BEmb10sch & -0.182 & -0.707 & 0.135 & 1.125 & 1.500 \\
\hline BEmb10cch & -0.416 & -0.629 & 0.616 & - & - \\
\hline BEmb20sch & -0.045 & -0.399 & 0.397 & 0.648 & 0.715 \\
\hline BEmb30sch & 0.011 & -0.031 & 0.041 & - & 0.244 \\
\hline
\end{tabular}

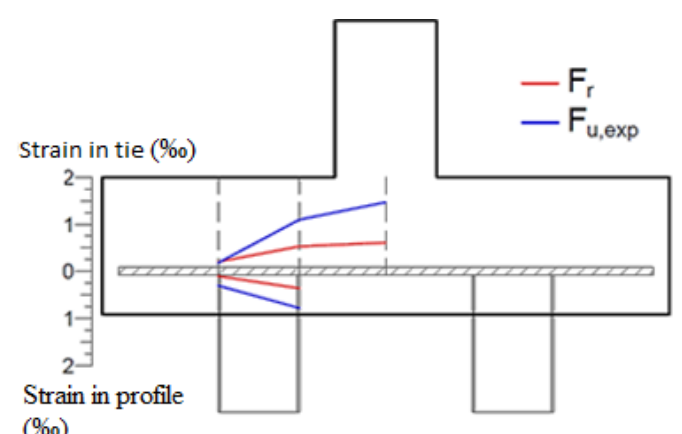

(\%)

Figure 13. Strain in tie and profile of the BEmb10sch model. 


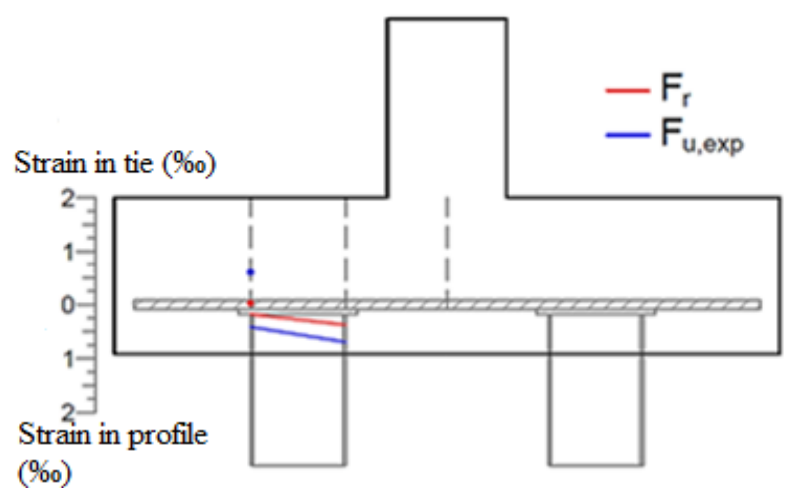

Figure 14. Strain in tie and profile of the BEmb10cch model.

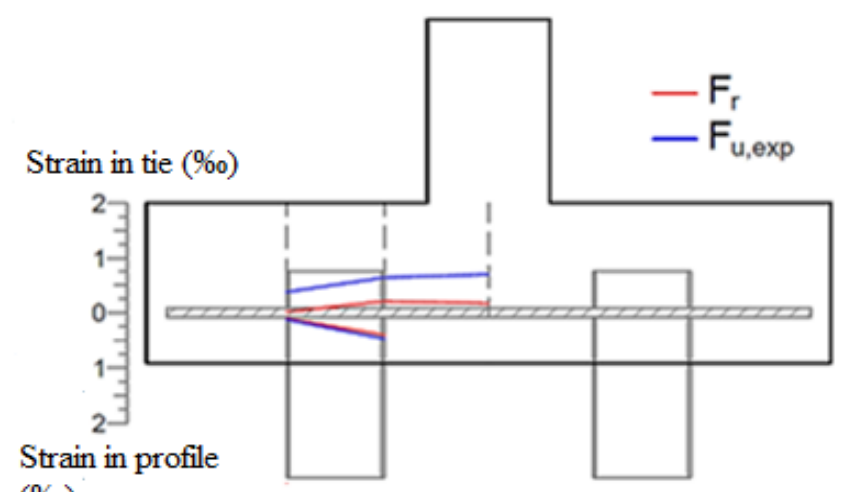

$(\%)$

Figure 15. Strain in tie and profile of the BEmb20sch model.

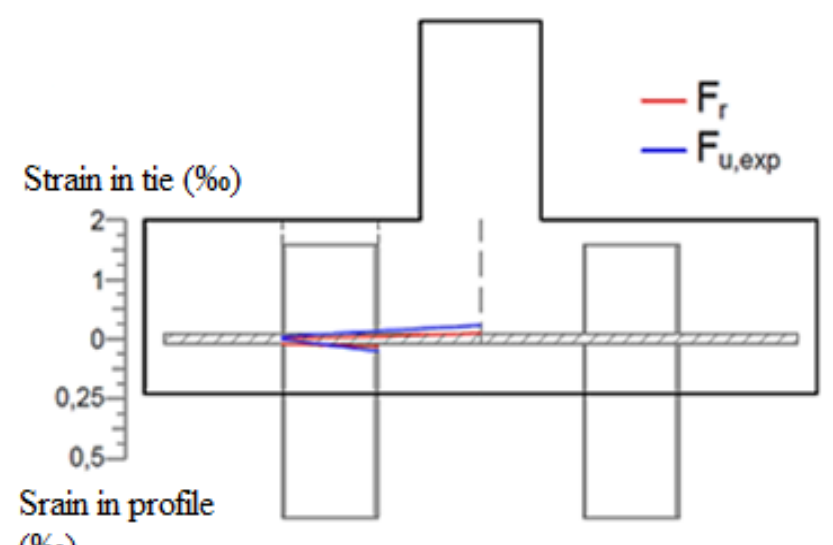

$(\%)$

Figure 16. Strain in tie and profile of the BEmb30sch model.

It was found that the deformation is not constant along the tie (e3, e4 and e5 strain gages), which corroborates the observations of Delalibera and Giongo [16] and Adebar et al. [17], who experimentally analyzed pile caps on concrete piles, finding similar results regarding deformations in the main tensile reinforcement (tie), that is, in the central region of the pile caps, the tie deformation is practically constant, decreasing when the bars of the tie cross the strut (at this point, there is an increase in the normal force, increasing the frictional force and therefore decreasing the tension in the steel bars). 
The flap closest to the end of the pile cap (strain gages e1) showed less deformation than the flap furthest from the end (strain gages e2). With this, it can be said that the profiles were not uniformly requested and, therefore, are subject to flexion-compression. Such behavior was also observed experimentally by Delalibera [18], Barros [19] and Munhoz [20].

As mentioned in item 2, it was considered that the connecting rod axis extends from $1 / 4$ of the column face to the geometric center of the pile section. The fact that the pile is subjected to flexion-compression indicates that the force from the strut does not act on the geometric center of the cross section of the pile, which alters the angle of inclination of the strut. This finding is most evident on the BEmb10sch and BEmb10cch models. In the BEmb30sch model, the profile obtained close deformations in the two flaps and in the tie, reinforcing the idea of ruin caused by punching.

Due to the difference in concrete strength of the tested pile caps, the analysis of the results obtained was based on the relative stress $\left(\sigma / f_{c, m}\right)$. For models without a top plate, the stresses were calculated considering the cross-sectional area of the metal profile, while for the model with a top plate, the area of the plate was considered. Table 9 shows the results of nodal stresses related to the ultimate force.

The BEmb10cch model presented a relative tension, in the upper nodal zone, approximately $57 \%$ higher than the BEmb10sch model, with the same inlay. This value is significant because, in the formulation presented by Blévot and Frémy [2], the tension in the upper nodal zone does not depend on the shape and/or type of pile used. The low values of relative stresses, also in the upper nodal zone, presented by the models BEmb20sch and BEmb30sch, can be explained by the fact that the greater length of the embedding influenced the colapse mode of the pile caps.

Table 9 - Active nodal stresses and relative nodal stresses

\begin{tabular}{|c|c|c|c|c|c|c|c|}
\hline Pile cap & $F_{u, \exp }(k N)$ & $\mathbf{f}_{\mathrm{c}, \mathrm{m}}(\mathrm{MPa})$ & Aest $\left(\mathrm{cm}^{2}\right)$ & $\sigma_{\mathrm{zni}}\left(\mathrm{kN} / \mathrm{cm}^{2}\right)$ & $\sigma_{\mathrm{zns}}\left(\mathrm{kN} / \mathrm{cm}^{2}\right)$ & $\sigma_{\mathbf{z n i}} / \mathbf{f}_{\mathbf{c}, \mathbf{m}}$ & $\sigma_{\mathbf{z n s}} / \mathbf{f}_{\mathbf{c}, \mathbf{m}}$ \\
\hline BEmb10sch & 578.65 & 17.95 & 18.96 & 30.52 & 1.85 & 1.7003 & 0.1032 \\
\hline BEmb10cch & 631.24 & 12.51 & 625 & 1.01 & 2.02 & 0.0807 & 0.1615 \\
\hline BEmb20sch & 355.55 & 17.42 & 18.96 & 18.75 & 1.14 & 1.0765 & 0.0653 \\
\hline BEmb30sch & 174.52 & 18.07 & 18.96 & 9.20 & 0.56 & 0.5094 & 0.0309 \\
\hline
\end{tabular}

In the lower nodal zone, the relative stress of the BEmb10sch model was $2106 \%$ higher than that of the BEmb10cch model. This value is justified by the use, in the calculation of the relative stress in the lower nodal zone of the BEmb10sch block, of the effective area of the steel profile, which is approximately 33 times smaller than the area of the plate, however, this verification is only illustrative because this. The relative stress value does not match what was observed experimentally, since both models showed failure by diagonal traction and not by crushing the concrete in the nodal region. Therefore, the area considered in the lower nodal region must be greater than the area of the effective cross section of the profile.

ABNT NBR 6122:2019 [8] recommends, in its section 8.5.6.1, that the minimum diameter for isolated piles without locking is $30 \mathrm{~cm}$, and for metal piles the diameter of the circle that circumscribes the cross section of the piles is considered. Thus, the stresses in the lower nodal zone were calculated again, considering the area defined by the circle circumscribed to the cross section of the profiles $\left(\mathrm{A}_{\text {circ }}\right)$. A collaborative concrete area was also considered equal to the area of confined concrete between the profile flaps, as illustrated by Figure 17, in which: $A_{\mathrm{sp}, \mathrm{cc}}$ is the total area to be considered; $h_{p}$ is the average height of the profiles; $b_{\mathrm{fm}}$ is the average between $b_{\mathrm{f} 1}$ and $b_{\mathrm{f} 2}$. Table 10 shows the stresses in the lower nodal zone, calculated with Equation 4, considering $A_{\text {est }}$ equal to $A_{\text {sp }, c c}$ and $A_{\text {circ }}$.

As the upper nodal zone presents a confluence of compression stresses, the premise that this region is subject to the multiaxial state of stresses was verified. For that, the limit stress for concrete under multiaxial stress state was recommended by NBR 6118: 2014 [1], calculated by Equation 7.

$\sigma_{\mathrm{zns}} \leq 1.0 \cdot \mathrm{f}_{\mathrm{c}}+0.9 \cdot \mathrm{f}_{\mathrm{ct}, \mathrm{sp}}$

Table 11 shows the limit stresses for the nodal regions, calculated according to NBR 6118:2014 [1] and with Blévot and Frémy [2], $\sigma_{\mathrm{zns}, \mathrm{lim}}$ is the limit stress for the upper nodal zone; $\sigma_{\mathrm{zn} i, \mathrm{lim}}$ is the limit stress for the lower nodal zone.

Table 12 presents the relationship between the limit stresses and the stresses obtained experimentally, considering the stresses of the lower nodal zone calculated with the different areas $\mathrm{A}_{\mathrm{sp}, \mathrm{cc}}$ and $\mathrm{A}_{\text {circ }}$, where: $\sigma_{\mathrm{zns}, \mathrm{exp}}$ is the stress obtained experimentally for the superior nodal zone; $\sigma_{\text {zniexp }}$ is the stress obtained experimentally for the lower nodal zone. Table 12 shows that the limit values of Blévot and Frémy [2] are very conservative and the normative values should be used only for models with $10 \mathrm{~cm}$ inlay of the metal profile, with and without the metal plate welded on top of it. In 
addition, in pile caps with $10 \mathrm{~cm}$ inlay, the values of nodal stresses in the lower zone were closer to the limit values when, in Equation 4, an area equal to is considered for $A_{\text {est. }}$.

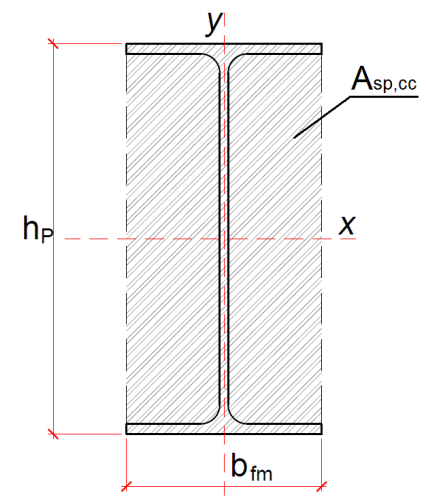

Figure 17. Collaborative concrete area to be considered

Table 10 - Tensions in the lower nodal region for Aest equal to Aesp,cc and Acirc

\begin{tabular}{|c|c|c|c|c|c|c|}
\hline \multirow{2}{*}{ Pile cap } & \multicolumn{2}{|c|}{$A_{\text {est }}\left(\mathbf{c m}^{2}\right)$} & \multicolumn{2}{|c|}{$\sigma_{\mathrm{zni}}\left(\mathrm{kN} / \mathrm{cm}^{2}\right)$} & \multicolumn{2}{|c|}{$\sigma_{\mathrm{zni}} / \mathbf{f}_{\mathrm{c}, \mathrm{m}}$} \\
\hline & $\mathbf{A}_{\text {sp,cc }}$ & $\mathbf{A}_{\text {circ }}$ & $\mathbf{A}_{\text {sp,cc }}$ & $\mathbf{A}_{\text {circ }}$ & $\mathbf{A}_{\text {sp,cc }}$ & $\mathbf{A}_{\text {circ }}$ \\
\hline BEmb10sch & 199.29 & 399.4 & 2.90 & 1.45 & 0.1618 & 0.0807 \\
\hline BEmb10cch & 625 & 399.4 & 1.01 & 1.01 & 0.0807 & 0.0807 \\
\hline BEmb20sch & 199.29 & 399.4 & 1.78 & 0.89 & 0.1024 & 0.0511 \\
\hline BEmb30sch & 199.29 & 399.4 & 0.88 & 0.44 & 0.0485 & 0.0242 \\
\hline
\end{tabular}

Note: $\mathrm{A}_{\text {sp,cc }}$ is the area of concrete defined by the area shown in Figure 17 and $\mathrm{A}_{\text {circ }}$ is the area of the circle circumscribed to the cross section of the steel profile

Table 11 - Stress limit for nodal regions.

\begin{tabular}{|c|c|c|c|c|c|}
\hline \multirow{2}{*}{ Pile cap } & \multicolumn{2}{|c|}{ NBR 6118:2014 [1] } & \multicolumn{2}{|c|}{ Blévot and Frémy [2] } & \multirow{2}{*}{$\frac{\text { Multiaxial state }}{\begin{array}{c}\sigma_{\mathrm{zns}, \lim } \\
\left(\mathrm{kN} / \mathrm{cm}^{2}\right)\end{array}}$} \\
\hline & $\sigma_{\mathrm{zns}, \lim }\left(\mathrm{kN} / \mathrm{cm}^{2}\right)$ & $\sigma_{\mathrm{zni}, \lim }\left(\mathrm{kN} / \mathrm{cm}^{2}\right)$ & $\sigma_{\mathrm{zns}, \lim }\left(\mathrm{kN} / \mathrm{cm}^{2}\right)$ & $\sigma_{\mathrm{zni}, \lim }\left(\mathrm{kN} / \mathrm{cm}^{2}\right)$ & \\
\hline BEmb10sch & 1.80 & 1.52 & 1.08 & 1.08 & 2.58 \\
\hline BEmb10cch & 1.25 & 1.06 & 0.75 & 0.75 & 1.92 \\
\hline BEmb20sch & 1.74 & 1.48 & 1.05 & 1.05 & 2.61 \\
\hline BEmb30sch & 1.81 & 1.53 & 1.08 & 1.08 & 2.80 \\
\hline
\end{tabular}

Table 12 - Relationship between observed stresses and limit stresses

\begin{tabular}{|c|c|c|c|c|c|c|c|}
\hline \multirow{3}{*}{ Pile cap } & \multicolumn{3}{|c|}{ NBR 6118:2014 [1] } & \multicolumn{3}{|c|}{ Blévot and Frémy [2] } & \multirow{3}{*}{$\frac{\text { Multiaxial state }}{\sigma_{\mathrm{zns}, \exp } / \sigma_{\mathrm{zns}, \mathrm{lim}}}$} \\
\hline & \multirow{2}{*}{$\sigma_{\mathrm{zns}, \exp } / \boldsymbol{\sigma}_{\mathrm{zns}, \lim }$} & \multicolumn{2}{|c|}{$\sigma_{z n i, \exp } / \sigma_{z n i, l i m}$} & \multirow{2}{*}{$\sigma_{\mathrm{zns}, \exp } / \sigma_{\mathrm{zns}, \mathrm{lim}}$} & \multicolumn{2}{|c|}{$\sigma_{z n i, e x p} / \sigma_{z n i, l i m}$} & \\
\hline & & Aesp,ce & $\mathbf{A}_{\text {circ }}$ & & Aesp,cc & $\mathbf{A}_{\text {circ }}$ & \\
\hline BEmb10sch & 1.03 & 1.91 & 0.95 & 1.72 & 2.70 & 1.35 & 0.72 \\
\hline BEmb10cch & 1.61 & 0.95 & 0.95 & 2.69 & 1.35 & 1.35 & 1.05 \\
\hline BEmb20sch & 0.65 & 1.21 & 0.60 & 1.09 & 1.71 & 0.85 & 0.44 \\
\hline BEmb30sch & 0.31 & 0.57 & 0.29 & 0.52 & 0.81 & 0.40 & 0.20 \\
\hline
\end{tabular}

Note: $\mathrm{A}_{\text {esp,cc }}$ is the area of concrete defined by the area shown in Figure 17 and $\mathrm{A}_{\text {circ }}$ is the area of the circle circumscribed to the cross section of the steel section

\section{CONCLUSIONS}

The models BEmb10sch and BEmb10cch, with $10 \mathrm{~cm}$ inlay, presented ruin by diagonal traction. As the embedding value was increased, the rupture started to be defined by the shear effect. This behavior does not depend on the type of pile or its geometric shape. Shearing collapse in reinforced concrete pile caps is exclusively related to the value of the inlay. 
The use of the welded top plate at the upper end of the profile increased the bearing capacity of the pile cap. Although the compressive strength of the concrete used in the BEmb10cch model showed less resistance, the block presented a final strength $9.18 \%$ greater than the ultimate strength of the BEmb10sch model. Therefore, it is concluded that the top plate in the pile, decreases the tension in the lower nodal region, thus increasing the ultimate resistance of the pile cap.

From the analysis of nodal stresses, it is recommended that for the lower nodal zone, at least the area of a rectangle should be considered, evolving the entire metallic profile, as suggested in Figure 17. It is worth mentioning, due to the limited number of experimental tests performed in this work and existing in the technical literature, these recommendations are applied only to pile caps on piles with the same characteristics as those tested in this work. It is also suggested that further studies on this topic be carried out, so that an analytical calculation model can be proposed.

The models with $10 \mathrm{~cm}$ inlay, presented rigid block behavior. Therefore, the use of metal piles did not affect the element's stiffness for this inlay. The small difference between the displacements of the BEmb10sch and BEmb10cch models proves that the steel plate did not interfere with the block stiffness. For models with $20 \mathrm{~cm}$ and $30 \mathrm{~cm}$ inlays, verification of the effect of bending and shear stress is necessary.

\section{ACKNOWLEDGMENTS}

The Faculty of Civil Engineering linked to the Federal University of Uberlândia, the company Gerdau S.A., for supporting research and FAPEMIG - Research Support Foundation of the State of Minas Gerais.

\section{REFERENCES}

[1] Associação Brasileira de Normas Técnicas, Design of Concrete Structures - Procedure, NBR 6118, 2014.

[2] Blévot, J., Frémy, R. “Semelles sur pieux. Analles de L’Institut Technique du Batiment.

[3] J. Schlaich and H. Schäfer, "Design and detailing of structural concrete using strut-and-tie models," Struct. Eng., vol. 69, no. 6, pp. 113-125, 1991.

[4] P. B. Fusco, Reinforcement Techniques for Concrete Structures, 2. ed. São Paulo: PINI, 2013. Portuguese only..

[5] Y. Xiao and L. Chen, "Behavior of model steel H-pile-to-pile-cap connections," J. Construct. Steel Res., vol. 80, no. 1, pp. 153-162, 2013.

[6] D. A. Velloso and F. R. Lopes, Foundations, Deep Foundation, vol. 2. São Paulo: Text Workshop, 2010. Portuguese only.

[7] Ohio. State of Ohio Department of Highways, Investigation of the Strength of the Connection Between a Concrete Cap and the Embedded End of a Steel h-Pile (Research Report 1). Ohio: SODH, 1947.

[8] Associação Brasileira de Normas Técnicas, Design and Execution of Foundations, NBR 6122, 2019.

[9] R. G. Slutter, "Full-scale pile cap tests and suggested design procedures," in Short Course-Semin. Anal. Des. Build. Found., vol. 1, Bethlehem, 1976, pp. 567-581.

[10] Associação Brasileira de Normas Técnicas, Design of Steel Structures and Mixed Steel and Concrete Structures for Buildings, NBR 8800,2008

[11] Associação Brasileira de Normas Técnicas, Metallic Materials - Tensile Test Part 1 - Test Method at Room Temperature, NBR $6892,2013$.

[12] Associação Brasileira de Normas Técnicas, Concrete - Cylindrical Specimen Compression Test, NBR 5739, 1994.

[13] Associação Brasileira de Normas Técnicas, Grout and Concrete - Determination of the Tensile Strength by Diametrical Compression of Cylindrical Specimens, NBR 7222, 2011.

[14] Associação Brasileira de Normas Técnicas, Concrete - Determination of the Elastic Modulus to Compression, NBR 8522, 2008.

[15] M. A. Tomaz, “Analysis of nodal stress on two-pile caps supported on steel piles,” M.S. thesis, Esc. Eng. Civ., Univ. Fed. Uberlândia, Uberlândia, 2018.

[16] R. G. Delalibera and J. S. Giongo, "Deformation in diagonals in two piles caps," Ibracon Struct. Mater. J., vol. 1, no. 2, pp. 121-157, 2008.

[17] P. Adebar, D. Kuchma, and M. P. Collins, "Strut-and-tie models for design of pile caps: an experimental study," ACI J., vol. 87, no. 1, pp. 81-92, 1990.

[18] R. G. Delalibera "Numerical and experimental analysis of two pile caps subjected to the action of centered and eccent ric load," Ph.D. dissertation, Esc. Eng. São Carlos, Univ. São Paulo, São Carlos, 2006.

[19] R. Barros, "Numerical and experimental analysis of two piles caps with external cup, partially embedded and embedded used in the column-pile caps connection,” Ph.D. dissertation, Esc. Eng. São Carlos, Univ. São Paulo, São Carlos, 2013. 
[20] F. S. Munhoz, "Experimental and numerical analysis of rigid two pile caps with column of square and rectangular sections and different reinforcement rates," Ph.D. dissertation, Esc. Eng. São Carlos, Univ. São Paulo, São Carlos, 2014.

Author contributions: Delalibera, R. G. Orientation, writing, essays and analysis of results. Tomaz, M. A. writing, essays and analysis of results. Giongo, J. S. writing and analyzing the results. Gonçalves, V. F. writing and analyzing the results.

Editors: Osvaldo Luís Manzoli, José Luiz Antunes de Oliveira e Sousa, Guilherme Aris Parsekian. 